\title{
The key to successful management of child care centres in Jordan
}

\author{
Loiy Bani Ismail ${ }^{1}$, Hala Hindawi ${ }^{1}$, Worud Awamleh $^{2}$ and Mohammad Alawamleh ${ }^{1 *}$ (D)
}

\section{${ }^{*}$ Correspondence:}

M.alawamleh@aum.edu.jo

${ }^{1}$ Business Administration

Department, American

University of Madaba, P.O.B.

2882, Amman 11821, Jordan

Full list of author information

is available at the end of the

article

\begin{abstract}
This research explores vital factors in effective management of care centres (CCs) in Jordan, and the role of key workers in establishing a nurturing family environment for optimal wellbeing of orphans. CCs in Jordan are the home for orphans who have lost one parent, both parents, or whom suffer from impoverishment. The study is based on triangulation of secondary data from relevant literature; individual, face-to-face, semi-structured interviews with CC directors $(n=3)$ concerning education, experience, management style and beliefs; questionnaires administered to CC employees $(n=30)$ interacting with orphans concerning education, prior work experience and steps taken to resolve issues; and observation of peer-to-peer and child-caregiver relationships; accommodation; and the extent of standardized routine administered in centres. This research recommends employing experienced directors who have a stated vision for the management of care centres, in addition to enhancing the reward system and salaries earned by employees at care centres, and training them to raise a prosperous and healthy generation. Furthermore, the establishment of a family based care centre exhibits a positive influence on children.
\end{abstract}

Keywords: Child welfare, Child welfare services and systems, Children, Care centres, Management, Residential care system, Orphans, Developing countries, Jordan

\section{Introduction}

The aim of this study is to investigate how orphans in care centres (CCs) in Jordan are living, and whether they are being given all the opportunities and guidance they fundamentally need.

This research aims to answer the following questions:

- How can care centers provide a family like environment for children?

- What are the educational level of directors and caregivers, and are they sufficient to provide children with what they ultimately need?

- How satisfied are employees working with children? And is their satisfaction level sufficient to motivate them to raise contented and healthy children?

- What are the negative behaviours exhibited by children? As have been mentioned by previous researchers. And are they related to orphanhood?

- What did observations reveal about how the orphans in care centres in Jordan are living? 
- What are society's responsibilities towards orphaned children?

The purpose of this study is to implement mechanisms that would enhance the management of care centers in Jordan.

This research made use of methodological triangulation, which was essential to acquire the needed data. An interviewer administered questionnaires to employees in CCs who directly interact with children. Furthermore, individual face-to-face semi-structured interviews were held with directors of CCs. Lastly, the peer-to-peer and child-caregivers relationships were observed, along with the accommodation of children in rooms, and the extent of standardized routine care administered in CCs.

Moreover, several visits to the Ministry of Social Development (MSD) were undertaken to collect essential data about the number of orphaned children in Jordan and the process undertaken by the Ministry regarding their care, and to obtain permission to visit and observe CCs in Jordan.

\section{Background}

Defining orphans

According to UNICEF (2015), an orphan was traditionally understood to be a child who has lost one or both parents; however, based on extensive research and experience, they not attest that an orphan should be understood in terms of factors such as poverty level, access to education and the family's ownership of property, irrespective of whether the parents are actually alive or deceased; however, the concept of losing a parent is still the major determinant of such factors in most orphan cases, and Faith to Action (2014) classified orphans according to either the loss of one parent (a single orphan) or the loss of both parents (a double orphan). They estimated that worldwide there are 153 million children (under the age of 16) who have lost one of their parents, and 17.8 million who have lost both.

\section{Why do they live in CCs?}

There are various reasons behind the placement of children in CCs; according to Faith to Action (2014) and UNICEF (2015), the major overarching reason is not the loss of parent(s) but poverty. More detailed analysis reveals complex impacts of poverty, with external intervention being necessary in some cases (whereby children are forcibly placed into CCs by government action due to suspected or proven abuse, violence, neglect, exploitation, conflict, mental illness, alcoholism or drug abuse). Internal intervention is more commonplace, with children being placed in CCs due to the death of one or both parents, or when living parents or guardians wish to provide their children with better living standards than they can provide due to poverty, homelessness, disability, chronic illness and natural disasters.

\section{Orphans' classification}

The MSD categorizes children based on their knowledge about the child's parents, as shown in Fig. 1: (1) children of known parentage, who (a) lost their father, or (b) their mother, or (c) both parents; (2) children separated from their biological parents because of abuse, divorce or imprisonment-these cases are considered as coming from broken 
families; and (3) children born out of wedlock, considered to be the results of illegitimate affairs. While the latter may appear anachronistic to Western eyes, in Jordan's conservative society it is a pertinent social concern due to its association with family breakdown and potential domestic conflicts (Eisner and Ghuneim 2013).

\section{Number of orphaned children in Jordan in 2015}

During the visit to MSD it was found that there are almost 822 children not living with their biological families who are under the Ministry's protection, and living in one of their CCs. According to the Ministry, the 822 children are either born out of wedlock, orphaned or as a result of broken families. In 2015 they recorded 169 orphaned children (new cases), comprising 95 females and 74 males. The most troubled children are born out of wedlock; while there are intrinsic factors that can be surmised to affect such children, including the lack of adequate parenting input, the main associated factor is stigmatization, which results in more serious impacts for such children in conservative cultures such as those of Asia (Liu and Heiland 2010), while conversely about a third of children in the US are born out of wedlock and experience relatively little stigma, with ethnic variations (Sigle-Rushton and McLanahan 2004). Stigmatization is understood as the labelling of children due to their separation from their biological parents in a way that manifests disapproval or humiliation; it can be actual (i.e., active hostility from other members of the community) or perceived (self-generated from the internalization of prevailing social mores). As of 2015 there were 348 children born out of wedlock residing in government CCs, comprising 191 females and 157 males.

In most cases of children separated from their biological parents due to being broken families the MSD intervenes for the child's best interests. In 2015, 305 children were recorded by the Ministry under this category, comprising 166 males and 139 females.

\section{Steps taken for children separated from their biological parents}

When children are discovered by the Ministry, there are three solutions to be implemented. Firstly, finding a foster family to care for the child, whereby the child resides with a family reimbursed for living expenses by the state. There are 1060 children in Jordan living with foster parents (MSD 2015).

Secondly, the official adoption is the process whereby the adopted child assumes similar rights as biological children in the foster family in addition to residing with them;

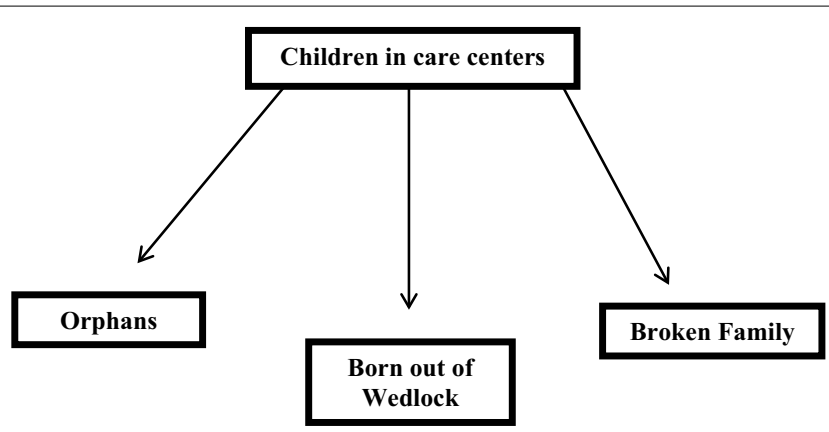

Fig. 1 Children in care centres (MSD 2015) 
unlike in Western contexts, the child does not adopt the foster family's name under the Arab-Islamic kafalah (guardianship) system; also, the child is not necessarily entitled to inheritance (a large proportion of the estate of the deceased is inherited by specified relations according to prescription in Islamic law and tradition, with some permissible discretionary bequests).

Lastly, CCs in Jordan, as around the world, form the mainstay of caring for orphans, providing them with love and support and helping shape their futures.

\section{Child care centres in Jordan}

Most CCs for orphaned children in Jordan are classified according to children's age group; this classification is a result of Islamic rules that prohibit males and females from living with one another after a certain age which is after adolescence.

Some CCs only welcome children from infancy to the age of 7 , afterwards children would live in other CCs that welcome children from the age of 7 until the age of 18 , in these CCs, children are separated from one another according to their gender.

On the other hand, other CCs in Jordan welcome children above the age of 2 years old, until the age of 14, then they would move to CCs until the age of 18 . In contrast, minority of CCs in Jordan welcome children from the instant they are orphaned until they are independent.

\section{Management of CCs in the literature}

Bettmann et al. (2015) focused on the perception of children's needs according to the staff and administration in the institution. When employees were interviewed, based on their experience they narrated that children needed all the fondness and support they could possibly get, and the issue of child's separation from parents is more problematic when the child is older. In addition, if the problem of separation was not handled by a responsible and experienced caregiver, delinquent behaviour in the child was likely to arise. In effect, the organizational structure of orphanages has a tremendous effect on the quality of care exerted to children, as well as the training that caregivers receive, which could be a barrier to effective care.

Furthermore, Nupponen (2005) discussed the management of CCs, where the job description of care givers and the director who is in charge of the management of the centre as a whole was emphasized. The directors of child CCs need to have the essential training and experience in business management to enhance their competencies for the management of centres, and the micro and macro influences should be kept in mind for the management and operations of such institutions. Correspondingly, the "one size fits all" management style does not fit this field in particular, because each child's case needs a special and diverse solution.

\section{Literature review}

This section analyses the literature related to the management of CCs gathered from journal articles and books. This section introduces readers to the definition and approaches of management, and highlights diverse perspectives regarding the management of CCs. Moreover, a situational analysis of CCs in Jordan and the qualifications required by child care workers is presented. 


\section{Defining management and management styles}

Management is the art and science of coordinating and directing the work of others to ensure that work is executed efficiently and effectively. Adizes (2004) believed that management is not only an art and science; it encompasses social and political values as well. The essential functions of management comprise planning, organizing, leading and controlling (Paladino 2007). Moreover, managers need to have a set of skills to oversee the work done by others, and to improve the coordination of different functions in an organization using conceptual, human and technical skills to effectively manage the organization as a whole and oversee the work of employees. The role of managers is ultimately reflected in producing results, administering organizational processes, entrepreneurship skills (creativity and risk taking) and the integration of the organization's overall functions (PAEI) (Adizes 2004); thus managers should develop their leadership capacity to increase efficiency and effectiveness.

\section{Results of parental separation on children}

In essence, CCs should have a distinct way of being managed; however, the particular cultural contexts in which CCs operate make it difficult to form universal policies due to diverse terminologies dealing with care for vulnerable children (Ainsworth and Thoburn 2014; MSD 2015). Nevertheless, the problems faced by such children do exhibit a worldwide pattern, with Siyavora (2010) exposing the tremendous physical, psychological and economic issues faced by orphans, including child labour, abuse, manipulation, mistreatment and even prostitution (UNICEF 2003). Other authors have highlighted the physical, mental and psychological effect that children endure while living in CCs themselves, such as powerlessness, a sense of insecurity, stigmatization and attachment disorders (Nowak-Fabrykowski and Piver 2008). Children in CCs are intrinsically vulnerable because they have lost their parents and/or have managed to survive neglect, abuse and poverty (Hearst et al. 2014); thus inappropriate CC management and supervision can result in a culture of abuse-Makame and Grantham-Mcgregor (2002) reported that severe punishment was the major problem faced by children living in CCs, with significant negative impacts on their wellbeing. While a longitudinal study by Van der Brug (2012) found that CC children's emotional well-being tremendously enhances over time, all children are entitled to safe and caring treatment as part of their human rights (UNICEF 2015).

\section{Approaches to the management of CCs}

Gharabaghi (2011) argued that control should not be an approach in organizations that deal with children, as it is a temporary solution that makes children cooperative pro tem, but which back fires in the long term. Rather, as issues arise, certain procedures should be implemented. Firstly, the manager should contemplate individual problems in context and avoid making rash decisions. When a problem arises, the first response by a manager should be to find the problem "interesting" rather than "problematic", which helps conceptualize and address the problem with a more nuanced and dispassionate perspective that addresses root causes, rather than making impulsive decisions.

Secondly, Gharabaghi (2011) emphasized the contingency of rules and protocols, which should be of secondary importance compared to consequences for people inside 
the organization (e.g., CC staff and residents). Decreasing the escalation of commitment enables managers to review original decisions and modify or reverse them if appropriate, rather than rigidly clinging to doctrinaire and useless procedures and policies (within the general parameters of law). The ultimate essence of CCs is the experiences that children have and the relationships formed with their caregivers, to which institutional policies should be supportive and ancillary. Furthermore, managers should understand that there are numerous perspectives on given issues, and that truth is perceived differently among individuals; considering the perspectives of children is essential to their emotional wellbeing and making effective CC decisions, particularly where challenging behaviour (e.g., self-harm, biting, spitting, vandalism, etc.) is involved (Hardman 2004; Jackson et al. 2001). Challenging behaviours should be handled by trained caregivers who are sensitive to the needs of troubled children, who handle these behaviours in a way that diffuses and does not reinforce them.

Carrà (2014) investigated the quality of CCs through the "relational quality" of the four dimensions of efficiency, effectiveness, relationality and subsidiarity. Efficiency includes the physical infrastructure such as rooms, staff members, training, working hours and activities. Effectiveness is the child's well-being and sense of involvement, including educational parameters and long-term solutions for when the child leaves residential care, either through adoption or kinship care. Relationality is the number of stakeholders involved in planning and applying the intervention. Subsidiarity concerns the mechanisms employed to empower and strengthen weak families, in order for children to resume lives with their biological families if possible (and safe).

Alternatively, Siyavora (2010) created a framework for the management of orphaned children that aims to create a family through four steps: awareness, interaction among generations (where siblings live together, to create a more natural family setting), family replication (placing children with foster parents or creating a family like atmosphere for the child, consisting of non-biological siblings) and a third-party emotional system that ensures caregivers' competence in resolving conflict, ensuring confidentiality, honesty and understanding.

\section{Situational analysis of care centres in Jordan}

A committee established by the MSD identified the strengths; weaknesses, opportunities and threats (SWOT) for the management of CCs in Jordan. They identified the strengths as the establishment of a family based atmosphere in child care institutions; they discovered that the SOS Children's Villages strategy that aims at ensuring a family based atmosphere for children ("a loving home for every child") is the optimum strategy for CCs in Jordan, thus a statute was issued by the Ministry making implementation of this strategy mandatory across CCs in Jordan.

On the other hand, various weaknesses have been revealed, such as children's constant mobility from one CC to the other, as well as their withdrawal from CCs. Allen and Vacca (2011) argued that child's constant mobility results in possible delinquent behaviour that might be exhibited, as a result of the child's environmental changes (friends, school, rules, routine, education and curriculum). However, Nyamukapa et al. (2010) found in their study that child's mobility does not affect the child's psychological well-being. In addition, the financial burdens of the establishment and operation 
of CCs are formidable, which is a major barrier for effective care provision in Jordan, a developing country that faces immense socio-economic challenges resulting from numerous influxes of asylum seekers from neighbouring countries. Moreover, the existence of CCs is essentially instrumental in the stigmatization of children who live in them, and being eternally labelled as "orphans" can stereotype such children for the rest of their lives, undermining their integration with society (Yendork and Somhlaba 2014).

Additionally, there is a chronic shortage of adequately qualified workers trained in the appropriate provision of care for children in CCs, particularly with regard to emotional wellbeing; this is a global problem, and most child care workers in residential care have a low educational level and limited experience (Ainsworth and Thoburn 2014). This relates to the lack of commensurate rewards for such challenging roles, particularly the long working hours and low remuneration of child care workers (Moss 2006); while there have been calls for many years to implement appropriate reward systems and raise the professional status of child care, little has been achieved to establish or sustain good performance (Pfau and Kay 2002). Another weakness revealed by the MSD committee was the lack of studies performed regarding orphaned children in Jordan. As for the opportunities regarding children's CCs, there is an evident governmental interest in the circumstances of orphaned children in Jordan, as well as the presence of volunteers and donors to support the work of residential care institutions. However, a noted threat was society's rejection of children raised in CCs (i.e., stigmatization). Table 1 illustrates the situational analysis of CCs in Jordan.

\section{Qualifications of childcare workers}

Child care workers need to have sufficient qualifications and experience in handling and raising children. Nupponen (2005) analysed the management of CCs and highlighted the importance of the job description for care givers and the director in charge of the

Table 1 Situational analysis of care centres in Jordan

\begin{tabular}{|c|c|}
\hline Strengths & Weaknesses \\
\hline $\begin{array}{l}\text { Applying the family based system for care centres (e.g., } \\
\text { SOS) }\end{array}$ & Children's withdrawal from care centres \\
\hline \multirow[t]{7}{*}{$\begin{array}{l}\text { MSD issued a statute that all care centres should be } \\
\text { based on a family atmosphere }\end{array}$} & $\begin{array}{l}\text { Children's constant mobility from one care centre to } \\
\text { another }\end{array}$ \\
\hline & High financial costs \\
\hline & Stigmatization \\
\hline & Unqualified care workers \\
\hline & Insufficient reward system for care workers \\
\hline & $\begin{array}{l}\text { Insufficient studies concerned with orphaned children } \\
\text { in Jordan }\end{array}$ \\
\hline & $\begin{array}{l}\text { The absence of systemized evaluation and follow-up } \\
\text { procedures for care centres }\end{array}$ \\
\hline Opportunities & Threats \\
\hline $\begin{array}{l}\text { The presence of volunteers and donors to support the } \\
\text { work of residential care institutions }\end{array}$ & Society's rejection of children raised in care centres \\
\hline $\begin{array}{l}\text { Government interest in improving the situation of } \\
\text { orphans in Jordan }\end{array}$ & \\
\hline
\end{tabular}


management of the centre as a whole, which with a good early foundation can have tremendous results on the future academic achievement and emotional wellbeing of CC children. According to the SOS Children's Villages of Jordan, the National Director strategically plans, ensures operational effectiveness, leads, manages and directs the association to efficiently and effectively deliver services and programs to families, children and youth, as well as ensuring a well financial position for the association through community donations and governmental subsidies. On the other hand, Nupponen (2005) claimed that the directors of child CCs need to have essential training and experience in business management to enhance their competencies for the management of centres, and they need to have appropriate adaptable leadership skills to devise tailored solutions for each child within the context of broader micro and macro influences on the management and operations of centres.

On another note, child care workers are the most influential part of a child's life, as they are the ones who interact with the child on a daily basis (Silva et al. 2014). While in some contexts it has been found that such workers perfectly understood their roles and responsibilities, emphasized building a long-lasting relationship with children, and acknowledged that children need to feel a sense of love and belonging (Holt and Kirwan 2012), more studies have found that child care workers in residential care have a low educational level and limited experience (Ainsworth and Thoburn 2014). Moreover, Siyavora (2010) discovered in a questionnaire presented to childcare workers about their previous experience dealing with orphaned children that only one respondent out of 20 had previous experience of working with orphaned children. Hardman (2004) recommended that there should be a clear job description, well developed training strategy and a supportive system that encourages staff to establish a sense of involvement and motivation.

\section{Methods}

Studies of child care generally pursue academic knowledge through a logical and orderly search for new and valuable information, which can subsequently be utilized by practitioners on their own initiative (Alawamleh 2012; Rajasekar et al. 2013), or they seek more immediate solutions for existential problems requiring expedient evidence upon which to base practice (Yeasmin and Rahman 2013). In both cases the research is grounded on a methodological paradigm reflecting ontological and epistemological assumptions concerning the nature of reality and how it can be understood (Yilmaz 2013).

This research generally fits the mixed-method approach, combing qualitative (subjective) and quantitative (objective) paradigms; it is referred to as triangulation. According to Yeasmin and Rahman (2013) triangulation is mostly used in social science, to enhance validity. In addition, it enriches a researcher's knowledge and understanding of certain phenomena. However, if the research was not evidently concentrated it will not produce adequate results, and data discrepancy will result (Jick 1979).

In this research, methodological triangulation has been used to properly enhance and validate the research. According to Bekhet and Zauszniewski (2012), methodological triangulation enables the researcher to acquire different perspectives regarding the phenomena being studied. Through the use of questionnaires intended for anyone who directly interacts with children (i.e., caregivers), semi-structured interviews for directors 
of care centers and observation intended for children aimed at studying their surroundings and behaviour, with respect to ethical consideration.

\section{Research aim}

According to Alawamleh (2012) and Bani Ismail (2012), there should be a clearly explained methodology in order for the research to be reliable. The aim of this research is to enhance the comprehension of the effective management of CCs in Jordan, and how the knowledge and education of caregivers and directors contribute to children's wellbeing. Hence, through the use of methodological triangulation, the variables shown in Table 2 are assessed for caregivers, directors and children.

\section{Primary data collection methods}

Primary research involves the gathering of new data by the researcher, thus it is generally used in particular research contexts such as pioneering research areas and case studies, while secondary research involves the critical analysis of the primary (and indeed secondary) research conducted by previous authors, such as systematic reviews and meta analysis (Alawamleh 2012; Bani Ismail 2012). In either case, the two main categorizations of data are quantitative (generally numerical, and associated with positivist research such as the natural sciences, used to test a priori theoretical hypotheses for generalization) and qualitative (in-depth exploration of the subjective views of human participants, often including researchers themselves, within particular social contexts); clearly both have advantages and disadvantages, and mixed methods research aims to triangulate the data from each paradigm to benefit from the strengths and minimize the weaknesses of each constituent data source (Alawamleh 2012; Bani Ismail 2012; McCusker and Gunaydin 2015), as used in this research. The questionnaires are intended for anyone who directly interacts with children (i.e., caregivers), gathering mainly quantitative data (although qualitative questions were included), while semi-structured interviews with directors of CCs and observation of children's surroundings and behaviour, comprise qualitative data.

\section{Questionnaire design}

The $\mathrm{ABC}$ questionnaire was translated into Arabic by the researcher to be comprehensible to the target population, and was administered by the interviewer, who distributed questionnaires to those who directly interact with children in care homes; these could

Table 2 The variables assessed through methodological triangulation

\begin{tabular}{lll}
\hline Caregivers & Directors & Children \\
\hline $\begin{array}{ll}\text { Education } \\
\text { Experience }\end{array}$ & Education & Behaviour \\
& Experience & $\begin{array}{c}\text { Relationship with non-biological } \\
\text { siblings }\end{array}$ \\
$\begin{array}{l}\text { How they perceive their job } \\
\text { Issue resolution with children, and }\end{array}$ & Leadership style & Relationship with their caregiver \\
$\begin{array}{l}\text { Income satisfaction level } \\
\text { Perception of children's negative } \\
\text { behaviour }\end{array}$ & Opcommodation \\
\hline
\end{tabular}


be caregivers, psychologists, counsellors and instructors for extracurricular activities in CCs. The questionnaire was introduced by a covering letter that ensures ultimate confidentiality, since the topic is sensitive, ensuring confidentiality increasing the authenticity of respondents' answers. The questions included a mix of closed- and open-ended questions; the former began with general demographic information about gender and income level per year (JOD), followed by five-point Likert scale questions about their satisfaction level with their income, and the level of importance placed to listening to a child's perspective as issues arise. In addition, multiple-choice questions about their education level, as well as questions regarding their previous and current experience with orphaned children, were included. Open-ended questions included in-depth questions regarding their opinion about child's ultimate needs, their job description, how they solve problems with children as they arise, and a contingency question after a close ended question about children's negative behaviour. Closed-ended questions were easy for the respondent to answer and the researcher to analyse, however, regarding this topic it was essential to gather in-depth information about children's behaviour in addition to caregivers' understanding and knowledge, which could not have been collected through closed-ended questions.

\section{Sampling method}

Stratified random sampling was administered to decrease economic and time costs and increase precision (Cochran 1977). CCs were chosen randomly from those registered with the MSD and only employees who directly interacted with children were asked to complete the questionnaire.

\section{Interview process}

The second methodology was individual face-to-face semi-structured interviews with randomly selected directors of CCs. According to Seale et al. (2010), respondents are able to easily and comfortably explain their answers in this technique, and the interviewer is able to elaborate ambiguous questions or questions that the interviewee did not fully comprehend initially. Moreover, according to Becker (2011), questions can be longer and more sophisticated if necessary, and the interviewer has the ability to comprehend body language and non-linguistic cues, however, they are more costly and potentially over-complex if executed by unskilled or novice researchers. Similarly Seale et al. (2010) noted that face-to-face interviews are time consuming, and further prone to interviewer bias, such as leading questions, which can only be decreased with conscious effort (Opdenakker 2006).

Most of the interview questions were derived from the framework constructed by Siyavora (2010), amended to fit the purpose of this study, with some supplementary questions generated by the researcher for the particular research context of CCs in Jordan. The questions aimed at knowing the director's job description, previous experience and most importantly their management and leadership style. All of the interviews were recorded through only note-taking and tape recording was not administered, in order, for the respondents to answer comfortably and authentically. Each individual interview took an average of $15-30 \mathrm{~min}$. 


\section{Observation}

As certain variables of interest to this study could not be assessed through interviews and questionnaires (e.g., the nature of accommodation and behavioural characteristics pertaining to the relationship between the caregiver and children), observation was used, to prevent respondents answering in a favourable manner to their self-presentation and indeed self-perception, to gain an authentic picture of the prevailing reality of day-to-day events in the four studied CCs, also decreasing the possibility of leading questions. Children's behaviour was observed with care professionals and non-biological siblings in the institution, along with the nature of accommodation and the standardized routine administered in the CCs. Each of these CCs been visited twice and each of these visits took about $8-10 \mathrm{~h}$.

\section{Findings and discussion}

\section{Questionnaire findings}

The questionnaires were distributed to 30 employees working at CCs. The questionnaire included qualitative and quantitative data, and the results are categorized accordingly.

\section{Quantitative results}

The quantitative data was analysed using SPSS. The results revealed that only one of the 30 respondents was male, with 29 being female. In relation to their income level per year (JOD), 50\% of the respondents earned less than 3000 per year; $60 \%$ were very dissatisfied and only $3.3 \%$ were satisfied with their working conditions, and participants clarified that their dissatisfaction arises from the disconnect between what they perceived to be low remuneration relative to their extensive workload and long working hours. One respondent earned 186 JOD per month for $480 \mathrm{~h}$, and her job demands that she sleeps at the CC. This reflects the global problem of child care workers having low wages and insufficient employment conditions (Moss 2006), and the need for reward systems to encourage and sustain good performance (Pfau and Kay 2002).

Siyavora (2010) found that only one of 20 respondents had previous experience of working with orphaned children before their current role, similar to the findings of this study (five out of 30). However, 33.3\% have been working at the CC for 1-5 years and $20 \%$ for more than 10 years. Furthermore, most childcare workers in this study had sufficient education, as shown in Fig. 2, unlike the findings of previous studies (Ainsworth and Thoburn 2014).

Many authors highlight the physical, mental and psychological effect that children endure while living in CCs, such as, powerlessness, a sense of insecurity, stigmatization and attachment disorders (Nowak-Fabrykowski and Piver 2008). In addition, Makame and Grantham-Mcgregor (2002) and Hearst et al. (2014) focused on the negative behaviour children might show as a result of their placement in CCs or their separation from their biological parents, and constant mobility and environmental changes were found to influence children's behaviour (Allen and Vacca 2011). Hence, caregivers were asked whether children show negative behaviour, and the causes of such behaviour in their opinion. Environmental influences were divided into current and previous (before admission to the current $\mathrm{CC}$ ). The results indicated that 28 out of 30 respondents believe that children show negative behaviour, 17 of whom considered the cause of 


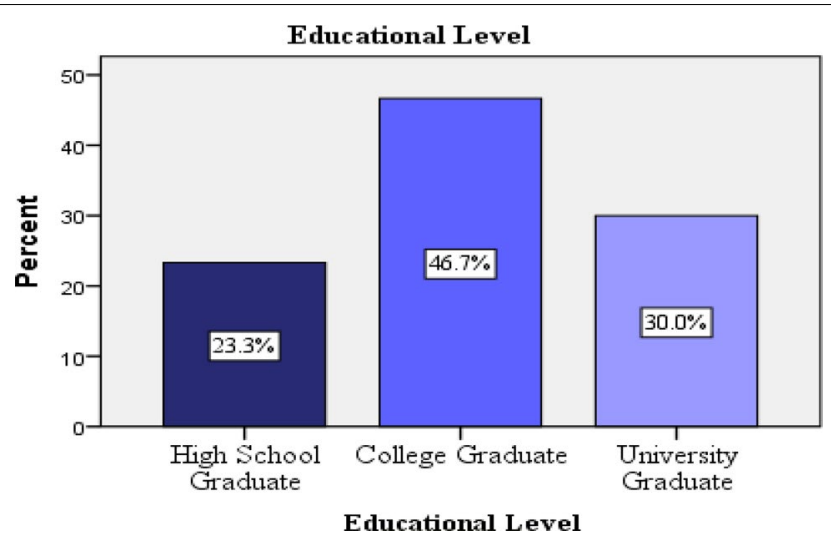

Fig. 2 Respondents' educational level

such behaviour to be previous environmental issues. Only seven respondents believed that children's negative behaviour is normal for children of that age. On the other hand, Nyamukapa et al. (2010) found that mobility does not affect the child's psychological well-being. In this study, only two caregivers believed that constant change of caregiver's affect children's negative behaviour (the causes of negative behaviours are explored in depth in the "Qualitative results" section). Figure 3 illustrates these results.

Regarding the importance placed on listening to children's perspectives as issues arise, $80 \%$ thought that this was crucial. This indicates caregivers' understanding of the importance placed at listening to children's perspective. Furthermore, working with children, especially those deprived of their parents' love and care, is generally considered to be a vocation imbued with love of children; however, when asked their motive for working with children, only eight respondents cited being fond of children. Of those who

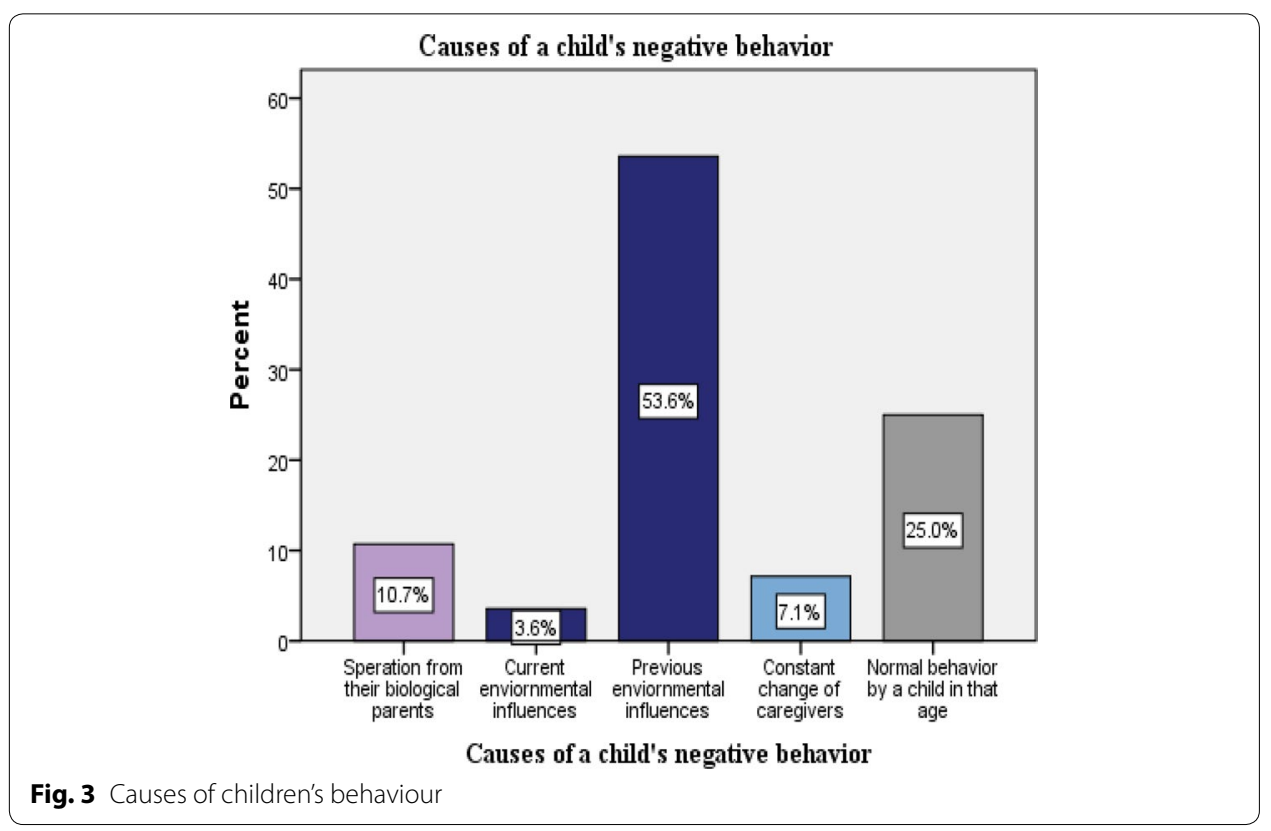


answered "other", they work with children because it offers them the chance of being a mother, due to not having their own biological children, as shown in Fig. 4.

\section{Qualitative results}

Qualitative data was gathered through open-ended questions that asked respondents to describe their job, what the child ultimately needs, the mechanisms adopted to resolve issues with children and description of children's negative behaviour. The collected answers were analysed through administering themes and relating the answers to relevant themes.

When respondents were asked to describe their role, 12 answered that it is the same as a mother's responsibility, and three were offended by referring to it as a "job", because they believe being a mother is not a job. On the other hand, nine respondents described their job as providing basic needs, such as preparing meals, checking the tidiness of children's rooms, monitoring hygiene and providing education. Clearly there was little professional understanding of the complex emotional needs of children, including a sense of love and belonging. However, counsellors and psychologists described their job as establishing programs to enhance the care children receive or extracurricular activities that enables children to learn through playing. Child care workers are an essential part of their children's lives; hence childcare workers need to know the needs of children. 25 out of 30 respondents believe that children need love, care, attention and security. The other respondents believe children need a family atmosphere, as well as a father figure, because most of the caregivers in these centres are females.

The researcher asked respondents regarding the mechanism adopted to resolve issues with children as they arise. 13 respondents answered as the mechanism adopted depends on the child and issues, because each child's case is different. Four respondents establish communication with the child; however, four respondents would instantly inform the psychiatrist or administration. In addition, five respondents resolve issues with children through punishment and reward. Surprisingly, three respondents declared that they do not intervene with the child's issues, and only one respondent searched for the root cause of the problem.

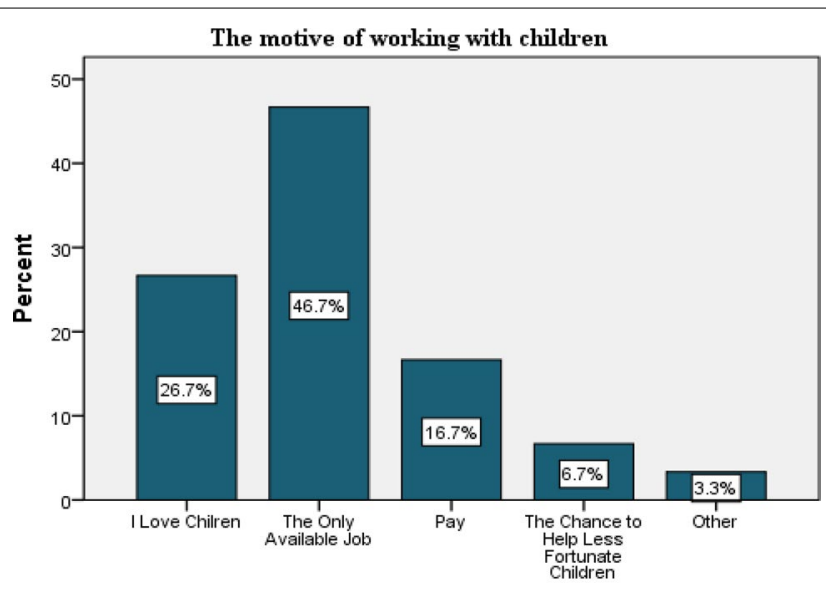

Fig. 4 Respondents' work influence

Work motive 
Moreover, as stated in the literature review, numerous researchers highlighted the negative behaviour that children might exhibit, such as violence, exploitation, a sense of insecurity, powerlessness and attachment disorders. However, this study revealed that most of the negative behaviours that children exhibit are sexual behaviour and violence, which were not highlighted in previous literature. The sexual behaviour that was acknowledged in this study was child-on-child sexual abuse. Additionally, the negative behaviour exhibited was aggression and violence in various forms, either hitting one another, teasing, non-compliance to care givers and self-mutilation. According to childcare workers, sexual behaviour and violence could begin from the age of 3 years onwards, and this behaviour peaks at the age of 12 years. When a child behaves in this manner at this early age, it is unlikely for the child to be aware of their behaviour; however, it could be a result of unconscious replication of sexual behaviour inflicted on them (current or previous). According to one of the respondents who have worked for more than 10 years at a CC in Jordan, these behaviours are more commonly displayed by children who come from broken families. The solution implemented in these situations is therapeutic sessions with a psychiatrist and alienating the child from other children. One of the respondents cited the role of societal stigmatization: "The society pities orphaned children"; "Children say "people look at us like we are beggars".

Since Jordanian culture is rooted in the principles of clans and the Bedouin tribal system, great importance is placed on knowing people's roots and origins, and wherever one goes across the country they are asked questions regarding their family name and which town they come from, which only makes matters worse for children whom do not know the identity of their parents; consequently, they are regarded with disrespect because their origins are unknown. Such children were often given a fake family name and a social security number beginning with " 2000 ", which also stigmatized children, however, extensive efforts and advocacy by the former director of SOS Children's Villages, Lina Mola, resulted in this regulation being amended.

Another result shown in the study that was not revealed by previous research is discrimination. Children in CCs are enrolled in normal schools, either private or public schools, depending on the CC's budget. One of the respondents revealed the difficulty in enrolling children in schools, because these schools do not wish to enrol orphans. Moreover, children at schools are treated differently regarding punishment and reward. This is also conditioned by the prevailing culture and society (i.e., stigmatization by educators).

\section{Interview findings}

Three individual face-to-face semi-structured interviews took place with directors of CCs. The questions in the interviews aimed to explore the directors' educational levels, experience, management styles, and steps taken in resolving issues with children. The results are explained below.

\section{Educational level}

Two directors had a bachelor's degree in Sociology and Philosophy, and the other had a college degree in Child Care and Development. None of the directors had any business management background, which they should have to enhance the management of CCs according to Nupponen (2005). 


\section{Experience}

Two directors had an experience working with orphaned children, and one had established a $\mathrm{CC}$ for females prior to working in the current $\mathrm{CC}$. The other director has been working at the CC since 1993; she was formerly a housekeeper, then a secretary, and finally director.

\section{Solving issues}

The first step taken when issues with children arise according to one of the directors was to establish communication with the child; if this solution was ineffective, then a psychologist was consulted. Another director responded that each child's case is different; hence, the solution implemented differs, in line with the call of Nupponen (2005) for tailored solutions. The remaining director cited an absence of problematic issues, but stated that if present they instantly solved by the psychologist. It has been argued that control should not be an approach in organizations that deal with children, and this was not the approach that directors use in managing their centres; however, none of the directors established the recommended law of interest (Gharabaghi 2011).

\section{Escalation of commitment}

The interviewees did not show escalation of commitment in response to the question that asked about their actions if decisions turn out to be wrong, for the reason that they responded with either admitting their mistake, reconsidering their decision or reversing the decision; Gharabaghi (2011) stated that directors should reverse their decisions if they turn out to be wrong.

\section{Providing a nurturing environment}

Two directors revealed that CCs can provide a nurturing family like environment through the establishment of the SOS Children's Villages model. In addition, the other director's response cited providing care and love to children. As Lassie et al. (2010) stated, the SOS Children's Villages' philosophy should be applied to other orphanages, because the notion of establishing a family for children who have lost their own biological ones has shown a positive influence on the children.

\section{Managerial qualities a director needs to possess}

According to all of the directors, the managerial qualities that directors need to possess are responsibility, knowledge, confidence, and rigidity in decision making, in addition to team spirit, as well as being passionate towards their job and children. This is extremely essential, for the reason that their work requires dealing with children, hence, passion enhances productivity. They also cited the strengths needed for managing the $\mathrm{CC}$.

\section{The constitution of effective management of CC}

The directors of CCs stated that for the management of CCs to be effective, there should be transparency to decrease corruption, and employees' knowledge about children and how to deal with them. In addition, the employees need to be passionate and satisfied. Furthermore, they noted the need to establish a family based CC, as advocated by Lassie et al. (2010). 


\section{Observation findings}

Extensive standardized routine was present in two CCs, which were not family based. Children's daily activities are known and standardized, and food is also scheduled by the MSD, which sends specific meals to be cooked for children and sets policies each centre should abide by, regardless of children's preferences. This was present in a family based $\mathrm{CC}$; such micro management is clearly not tailored to children's needs.

With regard to the relationship between children and their caregiver, in family based CCs a mother and a child relationship was evident; indeed, children were observed to refer to their caregiver as "mother". The caregivers themselves, in these CCs, feel that they are real mothers to these children, as one caregiver stated that the CC has given her a chance to become a mother, which otherwise would have been impossible. Such attitudes are not present in non-family based CCs. In one of the occurrences, while a child awoke during the observation, while the researcher was engaging in a conversation with the caregiver, the child came running calling his "mother" and ecstatically hugged her. On the other hand, in CC that was not family based, more of a superior and subordinate relationship was observed between children and their caregiver.

In one CC, a 3-year-old child introduced himself saying "Hello, my name is black Yazan". As a result of this surprising introduction, the caregiver elaborated dispassionately that "Everyone calls him that, because he is dark skinned". Therefore, the child was being taught and internalizing stigmatization and discrimination from an early age.

Nevertheless, a solid relationship between non-biological siblings was more evident in family based CCs. Moreover, a sense of love was felt between children. However, attention-seeking was prevalent, which could be normal behaviour for children of that age.

In relation to children's accommodation in rooms, in family based CCs an average of seven children live with a mother, distributed in two or three rooms, while the mother has a separate room for herself. On the other hand, in non-family based CCs the mother must share the same room with children.

\section{Conclusions}

The results reveal that directors and caregivers possess a sufficient educational level. The majority of caregivers believe that it is crucial to listen to children, and understand that children need love, care, security and attention. Moreover, they acknowledge that each child is different and requires different approaches, as well as the establishment of the needed communication with children in solving their problems. However, some caregivers lack understanding as they think that the correct way of handling issues that arise is through not intervening, or directly sending the child to a psychologist. Furthermore, most caregivers understand that their job is the same as any mother's job; as their role definition is usually that of a "mother substitute" meaning that they are expected to be like mothers but they are not as important as mothers. Few of them think that it there job is only about providing basic needs for children. In addition, a widespread lack of motivation is evident, since the majority of employees are very dissatisfied or dissatisfied with their income; furthermore, some chose this job not for the love of children, but because it is the only job available for them. 
Moreover, the increasing amount of standardized routine decreases the family atmosphere in CCs. In addition, evidently family based CCs provide children with the family atmosphere needed and the chance for children to have someone to call "mother".

In contrast to previous literature about children's negative behaviour, the study revealed that sexual behaviour and violence is the most prevalent type of negative behaviour children exhibit. In addition, society's mentality and culture is the number one cause of stigmatization and discrimination, which makes children feel unwanted and condemned, and some instances of this were encountered within CCs themselves.

\section{Recommendations and future directions}

The recommendation for further research is the usage of a larger sample, to enhance the validity and the ability to conclude generalization from the results. In addition to an in-depth research regarding children's mental, physical and psychological behaviour. As for the limitations faced by the research was time constraints, more time would have enabled the researcher to investigate the emergent issues in greater depth. Moreover, the complexity of acquiring consents from certain CCs to collect the required data was a barrier, with some centres demanded the presence of an employee from the administration when conducting the questionnaires, which conditioned caregivers to answer differently than they may have without the presence of an authority figure. Administering other methods to acquire necessary information from children, for example, questionnaires or interviews would yield further insights.

This research recommends employing experienced directors with a stated vision for the management of CCs to provide a nurturing and healthy environment for children. In addition, greatly enhancing the reward and salaries earned by employees at CCs would improve the job satisfaction (and performance) of existing personnel, as well as encouraging more motivated people to enter the profession. Moreover, training caregivers to enhance their understanding of children's needs and showing them the correct way of handling children's issues instead of depending on directors or counsellors would greatly increase the efficiency with which CCs provide for children's requirements, particularly their emotional needs or behavioural problems. This is best achieved in family based $\mathrm{CCs}$, which generally increase the self-esteem of resident children and promote more engagement with society. Furthermore, administering constructive training sessions to care givers regarding children's behaviour and attitudes and demonstrating the expectations required for a family based atmosphere, also how to manage and lessen children's sexual and negative behaviour.

Authors' contributions

All authors contributed equally to this work. All authors read and approved the final manuscript.

Authors' information

Loiy Bani Ismail is a Doctor of Business administration the American University of Madaba. He obtained his Ph.D. in Total Quality Management from Huddersfield University, UK. His research interest includes applying the best practices of knowledge management for an effective human resource management.

Hala Hindawi holds a Bachelor degree in Business Administration from the American University of Madaba. Her research interest includes the care centers, leadership styles, knowledge management and human resources management.

Worud Awamleh is a Doctor of Psychology and Special Education at Al-Balqa Applied University in Jordan. Her research interest includes special education; children care centers and apply the best practice to integrate children with special needs to the community.

Mohammad Alawamleh is a Doctor of Business administration at the American University of Madaba. He obtained his BSc in Computer Engineering, MSc in Digital Communication Systems from Loughborough University, UK and Ph.D. in Engineering Management from Coventry University. His research interest includes managerial and technical solution 
for collaboration between enterprises, virtual organisation, and risk management processes. He has published more than twenty refereed journal articles and conference proceedings.

\section{Author details}

${ }^{1}$ Business Administration Department, American University of Madaba, P.O.B. 2882, Amman 11821, Jordan. ${ }^{2}$ Psychology and Special Education Department, Princess Alia University College, Al-Balqa Applied University, Al-Salt 19117, Jordan.

\section{Acknowledgements}

This research received no specific grant from any funding agency in the public, commercial, or not-for-profit sectors.

\section{Competing interests}

The authors declare that they have no competing interests.

\section{Ethics approval and consent to participate}

Not applicable.

\section{Publisher's Note}

Springer Nature remains neutral with regard to jurisdictional claims in published maps and institutional affiliations.

Received: 17 February 2017 Accepted: 5 February 2018

Published online: 13 February 2018

\section{References}

Adizes, I. (2004). Management/mismanagement style: how to identify a style and what to do about it. Carpinteria: Adizes Institute.

Ainsworth, F., \& Thoburn, J. (2014). An exploration of the differential usage of residential childcare across national boundaries. International Journal of Social Welfare, 23(1), 16-24.

Alawamleh, M. (2012). Methodology to assess risks in virtual organization. GPEM, 1(2), 35-43.

Allen, B., \& Vacca, J. (2011). Bring back orphanages: An alternative to foster care? Children and Youth Services Review, 33(7), 1067-1071.

Bani Ismail, L. (2012). An evaluation of the implementation of Total Quality Management (TQM) within the construction sector in the United Kingdom and Jordan. Doctoral thesis, University of Huddersfield.

Becker, K. (2011). Face to face interviews: train the trainers module-fieldwork, Berlin. In: European Community's Seventh Framework Programme: Consortium to Perform Human Bio monitoring on a European Scale. http://www.eu-hbm. info/cophes/08FacetofacelnterviewKerstinBecker.pdf. Accessed 4 August 2016.

Bekhet, A., \& Zauszniewski, J. (2012). Methodological triangulation: An approach to understanding data. Nurse Researcher, 20(2), 40-43.

Bettmann, J., Mortensen, J., \& Akuoko, K. (2015). Orphanage caregivers' perception of children's emotional needs. Children and Youth Services Review, 49, 71-79.

Carrà, E. (2014). Residential care: an effective response to out-of-home children and young people? Child Family Social Work, 19(3), 253-262.

Cochran, W. (1977). Sampling techniques (3rd ed.). New York: Wiley.

Eisner, M., \& Ghuneim, L. (2013). Honor killing attitudes amongst adolescents in Amman, Jordan. Aggressive Behavior, 39(5), 405-417.

Faith to Action. (2014). Research. http://faithtoaction.org/wp-content/uploads/2014/03/Summary-of-Research4.pdf. Accessed 5 August 2016.

Gharabaghi, K. (2011). A child and youth care approach to residential care management. Relational Child \& Youth Care Practice, 24(1-2), 133-141.

Hardman, C. (2004). Analyzing the management of challenging behavior in Romanian orphanages: looking for ways forward. Support for Learning, 19(1), 38-44.

Hearst, M., Himes, J., Johnson, D., Kroupina, M., Syzdykova, A. Aidjanov, M., et al. (2014). Growth, nutritional, and developmental status of young children living in orphanages in Kazakhstan. Infant Mental Health Journal, 35(2), 94-101.

Holt, S., \& Kirwan, G. (2012). The "key" to successful transitions for young people leaving residential child care: The role of the keyworker. Child Care in Practice, 18(4), 371-392.

Jackson, S., Thomas, P., Marsh, H., \& Smethurst, C. (2001). Relationships between flow, self-concept, psychological skills, and performance. Journal of Applied Sport Psychology, 13(2), 129-143.

Jick, T. D. (1979). Mixing qualitative and quantitative methods: triangulation in action. Administrative Science Quarterly, 24(4), 602-611.

Lassie, Z., Mahmud, S., Syed, E., \& Janjua, N. (2010). Behavioral problems among children living in orphanage facilities of Karachi, Pakistan: Comparison of children in an SOS Village with those in conventional orphanages. Social Psychiatry and Psychiatric Epidemiology, 46(8), 787-796.

Liu, H., \& Heiland, F. (2010). "Should we get married?"The effect of parents marriage on out-of-wedlock children. Economic Inquiry, 50(1), 17-38.

Makame, V., \& Grantham-Mcgregor, S. (2002). Psychological well-being of orphans in Dar El Salaam, Tanzania. Acta Paediatrica, 91(4), 459-465.

McCusker, K., \& Gunaydin, S. (2015). Research using qualitative, quantitative or mixed methods and choice based on the research. Perfusion, 30(7), 537-542. 
Moss, P. (2006). Structures, understandings and discourses: Possibilities for re-envisioning the early childhood worker. Contemporary Issues in Early Childhood, 7(1), 30-41.

MSD (2015). Ministry of Social Development annual report 2015. www.mosd.gov.jo/images/report2015.pdf. Accessed 6 Aug 2016.

Nowak-Fabrykowski, K., \& Piver, P. (2008). Caring for foster children in the South: Why they did not have even one person to care for them. Education, 129(2), 192-201.

Nupponen, H. (2005). Leadership and management in child care services: Contextual factors and their impact on practice. Ph.D. thesis, Queensland University of Technology.

Nyamukapa, C. A., Gregson, S., Wambe, M., Mushore, P., Lopman, B., Mupambrieyi, Z., et al. (2010). Causes and consequences of psychological distress among orphans in eastern Zimbabwe. AlDS Care, 2(8), 988-996.

Opdenakker, R. (2006). Advantages and disadvantages of four interview techniques in qualitative research. Forum: Qualitative Social Research, 7(4), 11. http://www.qualitative-research.net/index.php/fqs/article/view/175/391. Accessed 5 August 2016

Paladino, B. (2007). Five key principles of corporate performance management. New York: Wiley.

Pfau, B. N., \& Kay, I.T. (2002). The five key elements of a total rewards and accountability orientation. Benefits Quarterly, 18(3), 7.

Rajasekar, S., Philominathan, P., \& Chinnathambi, V. (2013). Research methodology. Cornell University: arXiv. https://arxiv. org/pdf/physics/0601009.pdf. Accessed 5 August 2016.

Seale, C., Charteris-Black, J., MacFarlane, A., \& McPherson, A. (2010). Interviews and Internet forums: A comparison of two sources of qualitative data. Qualitative Health Research, 20(5), 595-606.

Sigle-Rushton, W., \& McLanahan, S. (2004). Father absence and child well-being: A critical review. In D. P. Moynihan, L. Rainwater, \& T. Smeeding (Eds.), The future of the family (pp. 116-155). New York: Russell Sage Foundation.

Silva, l., Gaspar, M., \& Anglin, J. (2014). Webster-Stratton incredible years basic parent programme (IY) in child care placements: Residential staff carers' satisfaction results. New York: Wiley.

Siyavora, A. (2010). Toward a grounded theory on the management of orphanages in South Africa and Zimbabwe. Ph.D. thesis, Walden University.

UNICEF. (2003). Africa's Orphaned generations. http://www.unicef.org/media/files/orphans.pdf. Accessed 4 August 2006.

UNICEF. (2015). Statement. http://www.unicef.org/media/media_45277.html. Accessed 5 August 2016.

Van der Brug, M. (2012). Strategies to bring about change: A longitudinal study on challenges and coping strategies of orphans and vulnerable children and adolescents in Namibia. African Journal of AIDS Research (AJAR), 11(3), 273-282.

Yeasmin, S., \& Rahman, K. (2013).'Triangulation' research methods as the tool of social science research. BUP Journal, 1(1), 154-163.

Yendork, J. \& Somhlaba, N. Z. (2014). The psychological functioning and experience following placement in orphanages: An exploratory study of orphanhood in Accra, Ghana. Ph.D. thesis, Stellenbosch University.

Yilmaz, K. (2013). Comparison of quantitative and qualitative research traditions: Epistemological, theoretical and methodological differences. European Journal of Education, 48(2), 311-325.

\section{Submit your manuscript to a SpringerOpen ${ }^{\circ}$ journal and benefit from:}

- Convenient online submission

- Rigorous peer review

- Open access: articles freely available online

- High visibility within the field

- Retaining the copyright to your article

Submit your next manuscript at $\boldsymbol{\nabla}$ springeropen.com 